\title{
Stage IV Uterine Corpus Cancer AJCC v8
}

National Cancer Institute

\section{Source}

National Cancer Institute. Stage IV Uterine Corpus Cancer A/CC v8. NCI Thesaurus. Code C139812.

Stage IV includes: IVA: T4, Any N, M0; IVB: Any T, Any N, M1. T4: Uterine corpus carcinoma or carcinosarcoma with tumor invading the bladder mucosa and/or bowel mucosa (bullous edema is not sufficient to classify a tumor as T4). M0: No distant metastasis. M1: Distant metastasis (includes metastasis to inguinal lymph nodes, intraperitoneal disease, lung, liver, or bone. It excludes metastasis to pelvic or para-aortic lymph nodes, vagina, uterine serosa, or adnexa). (from AJCC 8th Ed.) 